\title{
Relationship between emotional intelligence and empathy towards humans and animals
}

\author{
Raquel Gómez-Leal ${ }^{\text {Corresp., } 1}$, Ana Costa ${ }^{2}$, Alberto Megías-Robles ${ }^{1}$, Pablo Fernández-Berrocal ${ }^{1}$, Luísa Faria ${ }^{2}$ \\ 1 Department of Basic Psychology, Faculty of Psychology, University of Málaga, Málaga, Spain \\ 2 Faculty of Psychology and Education Sciences, University of Porto, Porto, Portugal \\ Corresponding Author: Raquel Gómez-Leal \\ Email address: raqgomlea@uma.es
}

Previous research has highlighted that Emotional Intelligence (EI) is related to an array of positive interpersonal behaviours, including greater human empathy. Nonetheless, although animals are an integral part of our lives, there is still a lack of clarity regarding the way in which El relates to empathy towards animals. The aim of this study was to investigate the relationship between El and empathy towards humans and animals. We used the Trait-Meta Mood Scale to assess El, the Interpersonal Reactivity Index to assess empathy for humans, and the Animal Empathy Scale to assess empathy for animals. Our findings revealed a positive relationship between empathy for humans and animals. The results also supported the idea that El is positively related to empathy for humans, while the relationship between El and empathy for animals was dependent on whether or not the participants had experience with pets. In addition, multiple regression analysis showed that the variables that best predicted empathy for animals were having a pet (or not), age, gender and human empathic concern. Finally, the relationship between human empathic concern and empathy for animals was stronger in participants who had pets. These findings provide a better understanding of the mechanisms underlying empathic behaviour and suggest that empathy for humans and animals can be influenced by different factors. Limitations and future lines of research are discussed. 
1 Relationship between emotional intelligence and empathy towards humans

2

3

4 Raquel Gómez-Leal ${ }^{1}$, Ana Costa $^{2}$, Alberto Megías-Robles ${ }^{1}$, Pablo Fernández-Berrocal, ${ }^{1}$ and 5

6

$7{ }^{1}$ Department of Basic Psychology, Faculty of Psychology, University of Málaga, Spain.

$8 \quad 2$ Faculty of Psychology and Education Sciences, University of Porto, Portugal
10

11

12

13

14

15

16

17

18

19

20

21

22

23

24

25

26

27

28

29

30

31

32

33

34 3 36

\section{and animals}

9

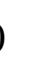

1

(2

(2)

14

15

7

9

0

2

3

5

7

8

29

1

2 Corresponding author

33 Raquel Gómez-Leal

34 University of Málaga

35 Faculty of Psychology, Department of Basic Psychology.

6 Campus Teatinos, s/n. 29071. Málaga, Spain

7 Email: raqgomlea@uma.es

38 


\section{Abstract}

Previous research has highlighted that Emotional Intelligence (EI) is related to an array of positive interpersonal behaviours, including greater human empathy. Nonetheless, although animals are an integral part of our lives, there is still a lack of clarity regarding the way in which EI relates to empathy towards animals. The aim of this study was to investigate the relationship between EI and empathy towards humans and animals. We used the Trait-Meta Mood Scale to assess EI, the Interpersonal Reactivity Index to assess empathy for humans, and the Animal Empathy Scale to assess empathy for animals. Our findings revealed a positive relationship between empathy for humans and animals. The results also supported the idea that EI is positively related to empathy for humans, while the relationship between EI and empathy for animals was dependent on whether or not the participants had experience with pets. In addition, multiple regression analysis showed that the variables that best predicted empathy for animals were having a pet (or not), age, gender and human empathic concern. Finally, the relationship between human empathic concern and empathy for animals was stronger in participants who had pets. These findings provide a better understanding of the mechanisms underlying empathic behaviour and suggest that empathy for humans and animals can be influenced by different factors. Limitations and future lines of research are discussed.

\section{Keywords}


Nowadays it is generally accepted that the intelligent use of emotions has a positive impact

78

79

80

81

82

83

84

85

86

87

88

89

90

91

92

93

94

95

96

97

98

99

100

101

102

103 on the psychological adaptation of the individual to their environment (Mayer \& Salovey, 1997; Salovey et al., 1999; Salovey et al., 1995), providing them with a better chance of success (Mayer et al., 2008). Based on this perspective, research conducted within the field of emotional intelligence (EI) has made a significant contribution to knowledge and evidence regarding the positive effects of emotions. In particular, research in recent decades indicates that an array of positive outcomes can be attributed to higher levels of EI, including improved well-being and mental health (Martins et al., 2010: İnce et al., 2019), academic or professional performance (Costa \& Faria, 2015; O’Boyle et al., 2011), prosocial behaviour and satisfaction with social networks (Ciarrochi et al., 2000; Mayer et al., 1999), lower levels of clinical symptomatology (Bastian et al., 2005; Megías et al., 2018a) and aggressive or disruptive behaviour (Brackett et al., 2004; Davis \& Humphrey, 2012; Lopes et al., 2011; Megías et al., 2018b).

In this regard, research has also been devoted towards exploring the relationship between EI and empathetic behaviours, namely the positive effects of EI on empathy for other humans. Nonetheless, to date no research has addressed the specific relationship between EI and empathy for animals, in spite of the fact that animals play a very important role in our society, and are an integral part of culture, leisure, well-being, work, and politics. In fact, public opinion would suggest that people who show sensitivity to nonhuman species have greater emotional abilities. However, the analysis of well-known cases, such as activists who violate human rights to save animals or even Hitler and his Nazi companions who were animal lovers (Paton, 1993), demonstrate that empathy for animals may not always relate to empathy for humans. This study presents a preliminary attempt to extend knowledge on the relationship between EI and empathy towards humans and animals.

\section{EI and empathy towards humans}

EI can be conceptualized as the capacity to process emotional information and comprises the "ability to perceive accurately, appraise, and express emotion; the ability to access and/or generate feelings when they facilitate thought; the ability to understand emotion and emotional 
104 knowledge; and the ability to regulate emotions to promote emotional and intellectual growth" 105 (Mayer \& Salovey, 1997, p. 10). Thus, both intrapersonal and interpersonal emotional abilities are considered to fall under this category of mental abilities (Mayer \& Salovey, 1997). constitutes a relevant factor in social interaction and prosocial behaviour (Gilet et al., 2013). Empathy, as a multidimensional construct that comprises emotional, cognitive and motivational components (Baron-Cohen \& Wheelwright, 2004; Cuff, Brown, Taylor, \& Howat, 2014), is based on the abilities to recognize, understand, and share the feelings of others (Davis, 1980; de Waal,

112 2008; Preston \& de Waal, 2002). More specifically, cognitive empathy reflects the way in which

113 we understand others, their experiences and emotions, emotional empathy involves the emotional

114 response to the experience of others and actually sharing that particular emotional state with the other (Smith, 2006), which often generates an empathic concern, understood as compassion or

116 motivational empathy, which leads a person to take action to relieve the suffering of others

117 (Eisenberg \& Miller, 1987; Pfattheicher et al., 2015).

118 Considering that perceiving and understanding emotion in others and emotional 119 awareness are abilities involved in EI, it might be reasonable to suppose that there is a positive 120 relationship between EI and empathy (Schutte et al., 2001). In fact, there are parallels between 121 some of the features of EI and empathy. Petrides et al. (2004) found evidence to suggest that the 122 trait EI models comprise affect-related functioning such as emotional awareness, empathy and 123 relationship skills. According to Mayer and Salovey (1997), an individual with optimum EI can 124 better perceive, understand, and manage their own emotions, and are more likely to be skilled at 125 generalizing these abilities of perceiving, understanding, and managing to the emotions of others.

126 Some authors have even argued that empathy is a result of EI, since the ability to reason about 127 emotions in ourselves and others will have an impact on the accurate interpretation and management of social interactions and emotional experiences (Mayer et al., 2008).

130 with higher EI are also more empathetic towards other people (Fitness \& Curtis, 2005; Mayer et 131 al., 1999; Schutte et al., 2001, 2005). This positive relationship has been established when 132 evaluating EI using different types of measures, including self-report (Fitness \& Curtis, 2005; 133 Salovey et al., 2002; Schutte et al., 2001) and performance tests (Ciarrochi et al., 2000; Mayer et 
134 al., 1999). In particular, some studies found that attention to emotions correlated positively with 135 the empathy dimensions of empathic involvement and personal distress (Aguilar-Luzón \& 136 Augusto, 2009; Extremera \& Fernández-Berrocal, 2004). A higher level of emotional clarity and

137 repair has also been positively associated with perspective taking and negatively associated with 138 personal distress, both of which are aspects of empathic behaviour (Aguilar-Luzón \& Augusto, 139 2009; Extremera \& Fernández-Berrocal, 2004; Ramos et al., 2007).

140 Although the relationship between EI and human empathy has been explored in the 141 literature, rather less attention has been paid to the issue of how EI relates to empathy directed 142 towards other entities, including empathy for animals. Given that empathy is related to the socio143 emotional abilities to recognize, understand and share the feelings of others, and that understanding 144 and being aware of the emotional signs in animals (with more or less phylogenetic proximity to 145 humans) can pose particular challenges since this is quite distinct from human interactions, the 146 relationship between EI and empathy towards animals could be quite different from the one 147 established with humans.

\section{Relationship between empathy directed to humans and to animals}

149 Over the past few decades, public opinion has shifted from the traditional conceptions of 150 animals as objects to be used by humans to a broader ethical perspective of care and compassion 151 towards them. In fact, the public attitudes to animals related to increasing sensitivity and concern 152 about animal use have developed in parallel with the stronger beliefs about the ability of animals 153 to experience pain and suffering, along with their cognitive abilities and their sentience (Cornish, 154 Wilson, Raubenheimer, \& McGreevy, 2018). This progressive change in society's attitudes 155 towards animals is most likely to be based on the increasing proximity with animals in our daily 156 life (e.g., pets) and on the countless contexts in which housed animals such as zoos, aquariums, 157 museums, sanctuaries, shelters, nature centres and others offer opportunities to have educational 158 experiences with animals and nature (Young, Khalil, \& Wharton, 2018).

159 Within the broader research area on the nature of empathy, the earliest studies exploring 160 the relationship between human individuals and other animals emerged and, in particular, these 161 works demonstrated that humans are able to feel empathy for animals (e.g., Emauz et al., 2016; 162 Paul, 2000). Moreover, empathy towards animals seem to have originated in a similar way as that 163 shown towards other humans (Ascione, 1992; Kohl, 2012; Ruckert, 2016). In his precursory 
164 research, Paul (2000) elaborated on the previous empathy definition put forward by Eisenberg 165 (1995) and specified that empathy towards animals entailed a vicarious emotional response to the emotions or states of animals, and the cognitive understanding of their thoughts or feelings. For

167 Drane (2009) empathy is the ability to feel what others are feeling, regardless of whether this comes from a direct relationship between humans or animals. Jorge Ritchman (cited in García, 2014) also extrapolated empathy towards our relationship with animals, considering this to be fundamental to our coexistence, since it allows us to perceive the damage that we can cause to other species, feel their suffering, or avoid it (García, 2014). More recently, a metanalytic review on empathy for animals defined empathy as a simulated emotional state that relies on the ability

173 to perceive, understand and care about the experiences or perspectives of another person or animal

174 (Young et al., 2018). Therefore, empathy towards animals comprises the same three abilities as empathy towards humans - affective empathy, cognitive empathy, and empathic concern (Cuff et al., 2014). Affective empathy is the ability to sense or physically experience the emotions of another (Cuff et al., 2014). For instance, when an individual observes an animal in a state of suffering, he/she may experience distress as if they were responding to the same stimulus (Eres, Decety, Louis, \& Molenberghs, 2015). Cognitive empathy is the ability to understand the experiences of others by recognizing and imagining their reality (Cuff et al., 2014), and might support (or not) our affective empathy. For instance, it supports our affective empathy when we believe the animal is suffering because we recognized that it is physically injured; or it does not provide such support, when, for instance, we understand that an animal is isolated due to their specific biological characteristics and it is not a sign of depression. Empathic concern, on the other hand, can motivate a person to take action and relieve the suffering of the animal (Eisenberg \& Miller, 1987; Pfattheicher et al., 2015), and in that case, an individual would help an animal that is injured or trapped.

Some authors consider that empathy for animals has a strong heritable component and can evolve differently depending on the particular species of animals (Bradshaw \& Paul, 2010). Research suggests that the development of empathic behaviour is due to its adaptative components,

191 which would enable pro-social behaviour and inhibit aggression. Another possibility explored by 192 some investigators is that the process of nurturing (e.g., providing food and shelter, care-giving) 193 infants and babies would have had an impact on the development of the empathic behaviours of 
194 humans, considering that the ability to empathetically respond to the distress shown by children is

195 a crucial component of the emotional nurturance process (de Waal, 2008).

196 Moreover, the literature also indicates that there is a positive relationship between the

197 empathy directed to humans and animals, although this is not of a high magnitude (Ellingsen et

198 al., 2010; Emauz et al., 2016; Paul, 2000). Other studies have also found that concerns about animal

199 suffering are associated with higher levels of empathy for humans (Ascione, 1992; Komorosky \&

200 O`Neal, 2015). However, when exploring whether individuals particularly characterized by high

201 levels of affection towards animals have high levels of affection towards humans, the results are

202 contradictory (Paul, 2005). For instance, a very high level of affection for animals can be related

203 to a displacement of affection from people to pets (Veevers, 1985). Therefore, it is not always

204 evident that in order to be empathetic towards animals the individual should also be empathetic

205 towards humans or vice versa. These findings suggest that empathy for humans and for animals

206 - whilst many times related - are probably not the same unitary construct, representing different

207 psychological concepts or, at least, separately influenced by specific factors (Paul, 2000; Paul,

208 2005). Perhaps the possibility that both types of empathy have shared and non-shared components

209 or because they act under the influence of specific moderator mechanisms could explain why

210 differences are often observed in the empathic responses shown towards human individuals and

211 other animals (Paul, 2000).

212 EI and empathy towards animals

213 To date, there are no reports regarding the relationship between EI and empathy directed

214 to animals of any kind, except humans. One could argue that EI is related to several positive

215 emotional outcomes such as empathy for humans (Fitness \& Curtis, 2005; Mayer et al., 1999;

216 Schutte et al., 2001, 2005) and that a similar association is likely to be found for empathy towards

217 animals. However, as previously described, the literature on empathy for animals has presented

218 mixed results, that is, supporting the association between attitudinal and prosocial behaviours

219 towards animals and towards people (Ellingsen et al., 2010; Emauz et al., 2016; Komorosky \&

220 O'Neal, 2015) or indicating that those behaviours can be independent (Paul, 2005). Moreover, the

221 dynamics of the relationships between individuals are far more complex than those established

222 with animals. One possibility is that the ability to understand and manage emotions based on

223 human interactions might prove to be insufficient to perceive and understand the emotions of

224 animals, which hinders the capacity of humans to empathise with them. Therefore, it is possible 
225 that for there to be an association between EI and empathy for animals, the influence of other 226 variables - such as the person's current experience with animals - could be critical. In this 227 regard, EI can be associated with empathy for humans and other positive human-oriented outcomes 228 but might not necessarily be correlated with animal-oriented constructs, for instance, advocating 229 for animal rights, being compassionate towards animals in distress, or taking a stance against the 230 use of animals for scientific purposes.

\section{Gender differences in EI and empathy}

232 Previous studies in the literature have revealed gender differences in EI, and in empathy 233 for humans and animals. Whilst in general, women score higher than men on the main factors that 234 constitute EI, this difference appears to depend on the type of instrument used. Specifically, when 235 a performance-based instrument is used, women score higher than men on all dimensions; 236 however, when using a self-report instrument, particularly the TMMS (Salovey et al., 1995), 237 women tend to score higher than men on the dimension of attention to emotions, and lower on the 238 dimensions of emotional clarity and repair (Cabello \& Fernández-Berrocal, 2015; Fernández239 Berrocal \& Extremera, 2008; Joseph \& Newman, 2010; Navarro-Bravo et al., 2019). Further, 240 previous studies indicate that women, compared with men, tend to exhibit higher levels of empathy 241 for both humans and animals (Angantyr et al., 2011; Klein \& Hodges, 2001; Paul, 2000; Serpell, 242 2004).

243 Aim

The main objective of this research was to investigate the relationship between EI and empathy for humans and animals. We conducted a detailed study through the analysis of several EI and empathy sub-dimensions. In addition, we examined the possible effect of previous experience with animals on these relationships. Based on the findings of the previous literature, we also explored possible gender-related differences in the scores of EI and empathy. We hypothesized that (1) there is a positive relationship between EI and empathy for animals; (2) there is a positive relationship between empathy for humans and empathy for animals; (3) with respect to the relationship between EI and empathy for animals, we conducted an exploratory analysis since it is not possible to formulate a clear hypothesis given the mixed findings reported in the previous literature; and finally, (4) we proposed that the relationships between EI, human empathy 
254 and empathy for animals may depend on the degree of proximity between the individual and

255 animals (operationalized according to whether they have pets or not).

256 Methods

257 Participants

258 The sample was composed of four hundred and seventy-one adult volunteers (34.4\% male).

259 They were recruited through advertisements at the University of Malaga, social networks, and

260 online platforms. The age of the participants ranged from 18 to 65 years with a mean of 26.15

261 years $(\mathrm{SD}=10.10)$. Two hundred and fifty-eight of the participants were pet owners. All

262 participants were informed that confidentiality and anonymity of the collected data would be 263 assured, and they were treated in accordance with the Helsinki declaration (World Medical 264 Association, 2008). The study was approved by The Research Ethics Committee of the University 265 of Málaga as part of the project PSI2017-84170-R (IRB approval number CEUMA 14-2019-H).

266

267

268

269

270

271

272

273

274

275

276

277

278

279

280

281

282

Procedure and instruments

Online questionnaires were completed by the participants through the LimeSurvey platform (http://limesurvey.org). The respondents accessed the questionnaires via an email link sent by the authors. An informed consent form was included in the survey, and the participants were assured of confidentiality and anonymity. To avoid missing data, the questionnaires were set up so that blank responses were not allowed. For each participant, this entire process took approximately 20 minutes to complete.

A description of each scale is detailed below:

Trait-Meta Mood Scale (TMMS; Salovey et al., 1995). The TMMS is a 24-item self-report scale widely used to assess EI. The questionnaire includes three sub-dimension scores: attention to emotions (awareness of our emotions, the ability to recognize our feelings and know what they mean), emotional clarity (ability to know, understand, distinguish and understand how emotions evolve, ability to integrate emotions in our thinking), and emotional repair (ability to regulate and control positive and negative emotions). Responses are given on a 5-point Likert type scale ranging from 1 ("Disagree strongly") to 5 ("Agree strongly"). We used the Spanish version of the scale (Fernández-Berrocal et al., 2004). In our study, the scale showed good internal consistency (Cronbach's alpha values of the sub-dimensions ranged between .85 and .91). 
284 measure empathy. This scale is composed of four sub-dimensions: perspective taking (ability of

285 subjects to adopt other people's point of view), empathic concern (tendency of subjects to

286 experience feelings of compassion and concern towards others), personal distress (tendency of 287 subjects to experience feelings of anxiety and discomfort when witnessing the negative 288 experiences of others) and fantasy (tendency of subjects to identify with fictional characters from 289 books and movies). Each item uses a 5-point Likert scale ranging from 1 ("Does not describe me 290 at all") to 5 ("Describes me very well"). We used the Spanish version of the scale (Escrivá et al., 291 2004). In our study, the scale showed adequate internal consistency (Cronbach's alpha value of 292 the total score was .79 and for the sub-dimensions this ranged between .66 and .76).

Animal Empathy Scale (AES; Paul, 2000) is a 22-item self-report scale used to measure 294 empathy for animals through the assessment of the individual's feelings about animals and their 295 treatment. The scale comprises items that enquire about both empathic relationships (e.g., "It 296

makes me sad to see an animal on its own in a cage"; "It upsets me when I see helpless old animals") and non-empathic relationships (e.g., "Dogs sometimes whine and whimper for no real reason"; "Sometimes I am amazed how upset people get when an old pets dies"). Responses are scored by a 9-point Likert scale ranging from 1 ("Disagree strongly”) to 9 (“Agree strongly”). We used the Spanish version of the scale in our study (La Torre Gómez, 2017). In our study, the scale showed adequate internal consistency (Cronbach's alpha value of the total score was .87).

Data analysis

First, descriptive statistics were computed to examine the characteristics of the scores of the measures employed, both for the total sample and divided by gender. Second, gender differences were contrasted using t-tests. Third, differences according to pet and non-pet ownership were examined by t-tests. Fourth, Pearson's correlations were conducted to explore associations between the study variables. Fifth, in order to verify if the association between empathy for animals and the variables of empathy for humans and EI are influenced by having pets, additional Pearson's corelation analyses were carried out by dividing the sample into pet owners and non-pet owners. Besides, using Fisher's Z-test, we tested if there were significant

311 differences between the human empathy and EI correlation and the animal empathy and EI 312 correlation, in the latter case for both the total sample and the sample divided according to pet 313 ownership status. Sixth, we conducted hierarchical multiple regression analyses in order to identify 
314 the study variables most strongly associated with empathy for animals. Pet ownership, gender and

315 age were entered at Step 1, the three EI sub-dimensions were entered at Step 2, and the four human

316 empathy sub-dimensions were entered at Step 3. Finally, we explored the possible moderating

317 effect of pet ownership on the significant relationships observed in the previous regression

318 analysis. Descriptive statistics, t-tests, Pearson's correlations, Fisher's Z-test and regression

319 analyses were carried out using SPSS ${ }^{\circ}$ version 24.0 (IBM Corporation, Armonk NY, USA) and

320 FZT computator (http://psych.unl.edu/psycrs/statpage/regression.html). SPSS PROCESS macro

321 2.16, Model 1 (Hayes, 2013) was used for the moderation analysis.

322

\section{Results}

324 Table 1 displays the descriptive statistics and gender differences for the variables included

325 in the study. We observed that women, in comparison with men, scored higher on the attention to

326 emotions sub-dimension of EI $(p<.01)$, in the perspective-taking, empathic concern, fantasy, and

327 personal distress sub-dimensions of human empathy $(p<.01)$ and on the scale of empathy for

328 animals $(p<.01)$. T-tests comparing pet owners and non-pet owners only revealed significant

329 differences on the scale of empathy for animals, where pet owners obtained a higher score $(p<$

330.01 ; see Table 1 for more details).

331

332

333

334

335

336

337

338

339

340

341

342
- Insert Table 1 -

Pearson's correlation analysis including the total sample (see Table 2) confirmed that scores on the attention to emotions sub-dimension of EI were positively related to all subdimensions of human empathy $(p s<.05)$; the emotional clarity sub-dimension was negatively related to personal distress, and positively related to fantasy and perspective-taking $(p \mathrm{~s}<.05)$; and the emotional repair sub-dimension was positively related to perspective-taking and fantasy, and negatively related to personal distress $(p s<.05)$. Regarding empathy for animals, the results revealed a positive relationship between the levels of empathy for animals and human empathy for the sub-dimensions of perspective-taking, fantasy and empathic concern. Moreover, higher levels of empathy for animals were related to higher EI, but only for the sub-dimension of attention to emotions.

- Insert Table 2 - 
Pearson's corelation analyses conducted by dividing the sample into pet owners and non-

344

345

346

347

348

349

350

351

352

353

354

355

356

357

358

359

360

361

362

363

364

365

366

367

368

369

370

371

372

pet owners (see Table 3) revealed a positive relationship between empathy for animals and human empathy for the sub-dimensions of perspective-taking and empathic concern in both samples. Moreover, a positive relationship was also revealed between empathy for animals and the human empathy sub-dimension of fantasy, but only for the sample of pet owners. With respect to the relationship between empathy for animals and EI, in the sample of non-pet owners, empathy for animals was not related to any of the sub-dimensions of EI. However, in the sample of pet owners, the results showed that higher levels of empathy for animals were related to higher EI for the subdimensions of attention to emotions and repair.

\section{- Insert Table 3 -}

When specific comparisons between correlations were made using Fisher's z-test, it was found that the EI sub-dimension of attention to emotions showed a significantly stronger positive relationship with the human empathy sub-dimensions of perspective-taking $(\mathrm{Z}=3.07, p<.01)$ and empathic concern $(Z=3.59, p<.01)$ than with empathy for animals. Emotional clarity showed a significantly stronger correlation with the human empathy sub-dimensions of perspective-taking $(Z=2.46, p<.05)$, fantasy $(Z=2.14, p<.05)$, and personal distress $(Z=3.46, p<.01)$ than with empathy for animals. Finally, emotional repair showed a significantly stronger relationship with the human empathy sub-dimensions of fantasy $(Z=2.67, p<.01)$ and personal distress $(Z=4.82$, $p<.01)$ than with empathy for animals. Finally, we did not find significant differences between the animal empathy and EI correlation when the sample was divided into pet owners and non-pet owners $(Z=0.76, \mathrm{NS}$, for attention to emotions, $Z=0.22$, NS, for emotional clarity $\mathrm{NS}, Z=1.29$, NS, for emotional repair).

In order to examine the study variables that can best predict empathy for animals, a hierarchical regression analysis was carried out with empathy for animals as criterion, and pet ownership, gender and age (Step 1), sub-dimensions of EI (Step 2), and sub-dimensions of human empathy (Step 3) as predictors. The significant predictors of empathy for animals included in the first step were pet ownership, gender and age; in the second step these were pet ownership, gender, and the attention and repair sub-dimensions of EI, and in the third step these were pet ownership, age, gender and the empathic concern sub-dimension of human empathy (see Table 4 for details). The final model accounted for 16.1 percent of the variance in empathy for animals. 
Finally, moderation analyses were conducted with EI and the human empathy sub-

375 dimensions that were significant predictors of empathy for animals. The results revealed that

376 having a pet had a moderating effect on the relationship between empathic concern and empathy

377 for animals, indicating that this relationship was stronger in participants who had pets (see Figure

3781 ; interaction effect $=-10.41,95 \%$ CI $[-18.38,-2.44])$. The rest of the sub-dimensions did not show 379 a significant moderation effect.

\section{Discussion}

Previous studies in the literature have shown that EI is related to positive aspects, such as better mental health, greater prosocial behaviours, and greater human empathy (Ciarrochi et al., 2000; Fitness \& Curtis, 2005; Martins et al., 2010). However, to date, the relationship between EI and empathy for animals has not been studied, despite the fact that animals are an increasingly important part of our society and everyday living. The present study attempted to delve more deeply into the relationship between EI and empathy for humans and for animals. More in-depth knowledge about these factors could help us to understand the differences that exist between personal emotional capacities and sensitivity to animals.

First, our study revealed that women, compared with men, showed a higher score on the EI sub-dimension of attention to emotions. This result is consistent with the previous literature and supports the hypothesis that women appear to have a greater ability to recognise feelings and know their meaning (Cabello \& Fernández-Berrocal, 2015; Fernández-Berrocal \& Extremera, 2008). We also found that women, compared with men, obtained higher scores on all the human empathy subdimensions. Empirical studies have indicated that women have a greater capacity than men for understanding the thoughts and feelings of others (Klein \& Hodges, 2001; Schieman \& Van Gundy, 2000). Finally, we observed that women scored significantly higher than men on empathy for animals. This finding is in accord with various studies showing that women tend to show a more positive attitudes towards animals (Furnham et al., 2003, Paul, 2000; Serpell, 2004). With regard to differences according to pet ownership, we found that pet owners showed higher scores 
402 with those reported in the previous literature, showing that familiarity with animals increases 403 empathy for them (Paul, 2000).

404 With respect to the Hypotheses 1 and 2, our results were consistent with most of the 405 findings in the literature (Ellingsen et al., 2010; Extremera \& Fernández-Berrocal, 2004; Findlay 406 et al., 2006; Fitness \& Curtis, 2005; Juntilla et al., 2006). Regarding Hypothesis 1, the results 407 confirmed that, in general, an adequate level of EI was related to higher levels of human empathy 408 (Fitness \& Curtis, 2005; Mayer et al., 1999; Schutte et al., 2001, 2005). However, it must be noted 409 that an excess of empathic involvement (i.e., higher scores on personal distress) could hinder the 410 ability to engage in emotionally intelligent behaviours (Extremera \& Fernández-Berrocal, 2004). 411 This latter assumption could explain the observation that levels of personal distress were 412 negatively related to emotional clarity and repair. With regard to Hypothesis 2, we found a positive 413 relationship between most of the human empathy sub-dimensions and empathy for animals. 414 Specifically, this study found that the emotional aspect of human empathy (the sub-dimension of 415 empathic concern) was the best predictor of empathy for animals. This finding is also in accord 416 with previous research (Ellingsen et al., 2010; Emauz et al., 2016; Paul, 2000) and suggests that 417 those individuals with higher scores on human empathy also have a more welfare-oriented attitude 418 towards animals. Whilst several theories could explain this result, in general, research indicates 419 that someone who is empathetic, that is, capable of adopting the point of view of animals, and 420 exhibits concern about them is likely to have similar feelings towards people (Eisenberg et al., 421 1992; Lockwood, 1983; Messent, 1983; Rossbach \& Wilson, 1992).

422 To address Hypothesis 3, we analyzed the relationship between EI and empathy for 423 animals. Analysis of the total sample revealed that higher levels of empathy for animals were only 424 positively related to the sub-dimension of attention to emotions. However, when we introduced 425 EI, together with human empathy, as a predictor of empathy for animals, only the relationship with 426 the empathic concern sub-dimension remained significant.

427 Finally, in order to verify if these relationships depended on the degree of familiarity (in 428 terms of pet ownership) that the person has with animals (Hypothesis 4), we conducted further 429 analyses by dividing the participants into two samples, that is, pet owners and non-pet owners. 430 Two main results were found. First, for the sample of pet owners, the results revealed a positive 431 correlation between the sub-dimensions of attention to emotions and repair with empathy for 
432 animals, whilst analysis of the sample of non-pet owners did not yield any significant relationship 433 between EI and empathy for animals. Second, the relationship between empathic concern and 434 empathy for animals was significantly stronger for those participants who had pets compared with 435 those without pets. These findings suggest that interaction with animals can influence the 436 relationship between EI, human empathy, and empathy for animals. Moreover, these results could 437 also reflect a potential bidirectional effect of the association established between empathy for 438 animals and pet ownership; individuals who have/had a pet report greater empathy for animals, 439 but also people with greater empathy for animals are also more likely to have pets and enjoy or 440 value their company.

441 In summary, the current findings do not support the notion that people who have better 442 emotional abilities are more empathetic towards animals. Our results instead appear to support the 443 idea that the proficiency for understanding and managing emotions is developed on the basis of 444 human interactions and such emotional abilities are insufficient to perceive and understand the 445 emotional signs of animals and consequently empathise with them. Direct interaction with animals 446 would thus be needed to improve these emotional abilities. To the best of our knowledge, this is 447 the first time that the relationship between EI and empathy for animals has been investigated. 448 Although EI has been linked to better interpersonal social relationships, prosocial behaviour, and 449 greater empathy for humans (Brackett et al., 2004; Gilet et al., 2013, Komorosky \& O`Neal, 2015; 450 Lopes et al., 2011), the results of our study indicate that EI may not be a determining factor in 451 452 empathy for animals, or at least suggests that the mechanisms underlying both types of empathy are influenced by different factors (Paul, 2000, 2005).

454 between empathy for humans and animals. However, it is important to consider that the 455 methodology employed was correlational and thus future lines of investigation should conduct experimental studies to determine causality between variables. Advances in the study of this relationship could have practical implications such as the promotion of interventions aimed at increasing human empathy levels through animal-assisted therapy. This type of therapy could be helpful for decreasing antisocial behaviours and aggressiveness among peers and, in addition, 460 could promote appropriate attitudes and respect for animal welfare. 
As limitations of the research, it is important to note that our sample was not gender

462

463

464

465

466

467

468

469

470

471

472

473

474

475

476

477

478

479

480

481

482

483

484

485

486

487

488

489

490

491 matched, with a greater number of women than men (34.4\% were men). Moreover, given that previous literature has shown that the ability to empathize is influenced and reinforced by similarity, age, gender, factors related to theory of mind or personality traits (de Waal, 2008; Kavanagh et al., 2013), future studies should explore possible differences in the empathy and EI relationship as a function of these factors. It is also important to note that, due to the correlationaltransversal design of this research, further exploration of the potential bidirectionality effects among the variables could not be tested in this study (e.g., empathy for animals and pet ownership).

Future research studies should aim to replicate these results in other countries, since there are cultural differences that could modify people's empathic values with respect to animals (Young et al., 2018). In addition, the degree of proximity to animals has only been operationalized in terms of pet ownership, thus excluding people who have other types of close relationships with animals, such as farmers, or people that work in other, similar professions. Therefore, future research should explore the various types of relationships that humans can have with animals. Finally, the questionnaires used in this research were self-report instruments, the responses of which are susceptible to possible response and introspective biases. In a similar vein, the reliability of the IRI questionnaire was not very high (Cronbach's alpha ranged between .66 and .76). In future investigations it might therefore be useful to work with behavioural and performance measures in order to address these issues.

\section{Conclusion}

The main objective of the current research was to clarify the relationship between EI and empathy for humans and animals in order to have a better understanding of the factors that underlie empathic behaviour towards animals and its relationship with empathy for humans. Our results revealed the existence of a positive relationship between both types of empathy (humans and animals). A positive relationship between EI and empathy for humans was also observed. However, these relationships were dependent on the participants' experience with animals. Overall, these results support previous literature regarding the positive relationship between EI and empathy for humans, but the mixed findings observed between EI and empathy for animals suggests a greater complexity in the relationships between these constructs, perhaps indicating that both types of empathy can be guided by different factors or represent different psychological 
492 constructs. Although preliminary conclusions can be drawn from these results, further 493 investigation is necessary in order to replicate these findings and better understand the common 494 and distinctive process involved in empathy for humans and animals, and their association with EI 495 abilities.

496

497

498

499

500 
501

502

503

504

505

506

507

508

509

510

511

512

513

514

515

516

517

518

519

520

521

522

523

524

525

526

527

528

529

530

531

532

\section{References}

Aguilar-Luzón, M. C., \& Augusto, J. M. (2009). Relationship between perceived emotional intelligence, personality and empathic behaviour in nursing students. Behavioural Psychology, 17, 351-364.

Angantyr, M., Eklund, J., \& Hansen, E. M. (2011). A comparison of empathy for humans and empathy for animals. Anthrozoös, 24(4),

369-377. https://doi.org/10.2752/175303711X13159027359764

Ascione, F. R. (1992). Enhancing children's attitudes about the humane treatment of animals: Generalization to human-directed empathy. Anthrozoös 5(3), 176-191. https://doi.org/10.2752/089279392787011421

Baron-Cohen, S., \& Wheelwright, S. (2004). The empathy quotient: An investigation of adults with Asperger syndrome or high functioning autism, and normal sex differences. Journal of Autism and Developmental Disorders, 34, 163-175. https://doi.org/10.1023/B:JADD.0000022607.19833.00

Bastian, V. A., Burns, N. R., \& Nettelbeck, T. (2005). Emotional intelligence predicts life skills, but not as well as personality and cognitive abilities. Personality and Individual Differences, 39(6), 1135-1145. https://doi.org/10.1016/j.paid.2005.04.006

Brackett, M. A., Mayer, J. D., \& Warner, R. M. (2004). Emotional intelligence and its relation to everyday behaviour. Personality and Individual Differences, 36, 1387-1402. https://doi.org/10.1016/S0191-8869(03)00236-8

Bradshaw, J. W., \& Paul, E. S. (2010). Could empathy for animals have been an adaptation in the evolution of Homo sapiens. Animal Welfare, 19(1), 107-112.

Cabello, R., \& Fernández-Berrocal, P. (2015). Implicit theories and ability emotional intelligence. Frontiers in Psychology. 6:700. https://doi.org/10.3389/fpsyg.2015.00700

Ciarrochi, J. V., Chan, A. Y. C., \& Caputi, P. (2000). A critical evaluation of the emotional intelligence construct. Personality and Individual Differences, 28, 539-561. https://doi.org/10.1016/S0191-8869(99)00119-1

Cohen, J. (1988). Statistical power analysis for the behavioral sciences (2nd edition). Hillsdale, NJ: Erlbaum.

Cornish, A., Wilson, B., Raubenheimer, D., \& McGreevy, P. (2018). Demographics regarding belief in non-human animal sentience and emotional empathy with animals: A pilot study 
533

534

535

536

537

538

539

540

541

542

543

544

545

546

547

548

549

550

551

552

553

554

555

556

557

558

559

560

561

562

563

among attendees of an animal welfare symposium. Animals, 8(10), 174. https://doi.org/10.3390/ani8100174

Costa, A., \& Faria, L. (2015). The impact of emotional intelligence on academic achievement: A longitudinal study in Portuguese secondary school. Learning and Individual Differences, 37, 38-47. https://doi.org/10.1016/j.lindif.2014.11.011

Cuff, B. M. P., Brown, S. J., Taylor, L., \& Howat, D. J. (2014). Empathy: A review of the concept. Emotion Review 8(2), 144-153. https://doi.org/10.1177/1754073914558466

Davis, M. H. (1980). A multidimensional approach to individual differences in empathy. Journal Supplemental Abstract Service Catalog of Selected Documents in Psychology, 10, 1-17.

Davis, M. H. (1983). Measuring individual differences in empathy: Evidence for a multidimensional approach. Journal of Personality and Social Psychology, 44(1), 113117. https://doi.org/10.1037/0022-3514.44.1.113

Davis, S., \& Humphrey, N. (2012) Emotional Intelligence predicts adolescent mental health beyond personality and cognitive ability. Personality and Individual Differences, 52(2), 144-149. https://doi.org/10.1016/j.paid.2011.09.016

De Waal, F. B. (2008). Putting the altruism back into altruism: The evolution of empathy. Annual $\begin{array}{llll}\text { Review } & \text { of } & \text { Psychology, } & \text { 279-300. }\end{array}$ https://doi.org/10.1146/annurev.psych.59.103006.093625

Drane, J. (2009). Sufrimiento y depresión: Cómo la comprensión y la fe pueden ser de utilidad. Bogotá: San Pablo.

Eisenberg, N. (1995). Empathy. In A. R. Manstead \& M. Hewstone (Eds.), The Blackwell Encyclopaedia of Social Psychology (pp. 203-208). Oxford: Blackwell.

Eisenberg, N., Fabes, R. A., Carlo, G., Troyer, D., Speer, A. L., Karbon, M., \& Switzer, G. (1992). The relations of maternal practices and characteristics to children's vicarious emotional responsiveness. Child Development, 63, 583-602. https://doi.org/10.1111/j.14678624.1992.tb01648.x

Eisenberg, N., \& Miller, P.A. (1987). The relation of empathy to prosocial and related behaviours. Psychological Bulletin, 101, 91-119.

Ellingsen, K., Zanella, A. J., Bjerkås, E., \& Indrebø, A. (2010). The relationship between empathy, perception of pain and attitudes toward pets among Norwegian dog owners. Anthrozoös, 23, 231-243. https://doi.org/10.2752/175303710X12750451258931 
564 Emauz, A., Gaspar, A., Esteves, F., \& Carvalhosa, S. F. (2016). Adaptação da Escala de Empatia

565

566

567

568

569

570

571

572

573

574

575

576

577

578

579

580

581

582

583

584

585

586

587

588

589

590

591

592

593 pelos Animais (EEA) para a população portuguesa. Análise Psicológica, 34, 189-201. http://dx.doi.org/10.14417/ap.1049

Eres, R., Decety, J., Louis, W. R., \& Molenberghs, P. (2015). Individual differences in local gray matter density are associated with differences in affective and cognitive empathy. NeuroImage 117, 305-310. https://doi.org/10.1016/j.neuroimage.2015.05.038

Escrivá, V., Navarro, M., \& García, P. (2004). La medida de la empatía: Análisis del Interpersonal Reactivity Index. Psicothema, 16(2), 255-260.

Extremera, N., \& Fernández-Berrocal, P. (2004). Emotional intelligence, quality of interpersonal relationships and empathy in university students. Clínica y Salud, 15, 117-137.

Fernández-Berrocal, P., \& Extremera, N. (2008). A review of trait meta-mood research. In A. M. Columbus (Ed.), Advances in Psychology Research (Vol. 55, pp. 17-55). New York, NY: Nova Publishers.

Fernández-Berrocal, P., Extremera, N., \& Ramos, N. (2004). Validity and reliability of the Spanish modified version of the Trait Meta-Mood Scale. Psychological Reports, 94, 751-755. https://doi.org/10.2466/pr0.94.3.751-755

Fitness, J., \& Curtis, M. (2005). Emotional intelligence and the trait meta-mood scale: Relationships with empathy, attributional complexity, self-control and response to interpersonal conflict. E-Journal of Applied Psychology: Social section, 1, 50-62.

Furnham, A., McManus, C., \& Scott, D. (2003). Personality, empathy and attitudes to animal welfare. Anthrozoös, 16(2), 135-146. https://doi.org/10.2752/089279303786992260

García, A. (2014). Para no ceder a la hipnosis. Crítica y revelación en la poesía de Jorge Ritchman. Madrid: Pontificia Universidad Javeriana

Gilet, A.-L., Mella, N., Studer, J., Gruhn, D., \& Labouvie-Vief, G. (2013). Assessing dispositional empathy in adults: A French validation of the Interpersonal Reactivity Index (IRI). Canadian Journal of Behavioural Science/Revue Canadienne des Sciences du Comportement, 45, 42-48. https://doi.org/10.1037/a0030425

Gómez-Leal, R., Megías-Robles, A., Gutiérrez-Cobo, M. J., Cabello, R., Fernández-Abascal, E. G., \& Fernández-Berrocal, P. (2019). Relationship between the Dark Triad and depressive symptoms. PeerJ, 7, e8120. https://doi.org/10.7717/peerj.8120 
594 Hayes, A. F. (2013). Introduction to mediation, moderation, and conditional process analysis: a

595

596

597

598

599

600

601

602

603

604

605

606

607

608

609

610

611

612

613

614

615

616

617

618

619

620

621

622

623 regression-based approach. New York: Guilford Press

İnce, B., Şimsek, Ö. F., \& Özbek, L. (2019). Attachment and depression: The mediating roles of personal life projects and emotional intelligence. Current Psychology, 39 1910-1920. https://doi.org/10.1007/s12144-019-0136-4

Joseph, D. L., \& Newman, D. A. (2010). Emotional intelligence: an integrative meta-analysis and cascading model. Journal of Applied Psychology, 95, 54-78. https://doi.org/ 10.1037/a0017286

Kavanagh, P. S., Signal, T. D., \& Taylor, N. (2013). The dark triad and animal cruelty: Dark personalities, dark attitudes, and dark behaviors. Personality and Individual Differences, 55(6), 666-670. https://doi.org/10.1016/j.paid.2013.05.019

Klein, K. J. K., \& Hodges, S. D. (2001). Gender differences, motivation, and empathic accuracy: When it pays to understand. Personality and Social Psychology Bulletin, 27, 720-730. https://doi.org/10.1177/0146167201276007

Kohl, R. (2012). Prison animal programs: A brief review of the literature. Milford, MA: Office of Strategic Planning and Research, Massachusetts Department of Correction.

Komorosky, D., \& O'Neal, K. (2015). The development of empathy and prosocial behavior through humane education, restorative justice, and animal-assisted programs. Contemporary Justice Review, 1-12. https://doi.org/10.1080/10282580.2015.1093684.

La Torre Gómez, R. S. (2017). Adaptación de la Escala de Empatía Animal en Estudiantes Universitarios de la Provincia del Santa. (Tesis doctoral). Universidad Cesar Vallejo, Chimbote, (Perú).

Lopes, P. N., Nezlek, J. B., Extremera, N., Hertel, J., Fernández-Berrocal, P., Schütz, A., \& Salovey, P. (2011). Emotion regulation and the quality of social interaction: Does the ability to evaluate emotional situations and identify effective responses matter? Journal of Personality, 79(2), 429-467.https://doi.org/10.1111/j.1467-6494.2010.00689.x

Martins, A., Ramalho, N., \& Morin, E. (2010). A comprehensive meta-analysis of the relationship between emotional intelligence and health. Journal of Personality and Individual Differences, 49, 554-564. https://doi.org/10.1016/j.paid.2010.05.029 
624 Mayer, J. D., Caruso, D., \& Salovey, P. (1999). Emotional intelligence meets traditional standards

625

626

627

628

629

630

631

632

633

634

635

636

637

638

639

640

641

642

643

644

645

646

647

648

649

650

651

652

653

654 for an intelligence. Intelligence, 27, 267-298. https://doi.org/10.1016/S01602896(99)00016-1

Mayer, J. D., Roberts, R. D., \& Barsade, S. G. (2008). Human abilities: Emotional intelligence.

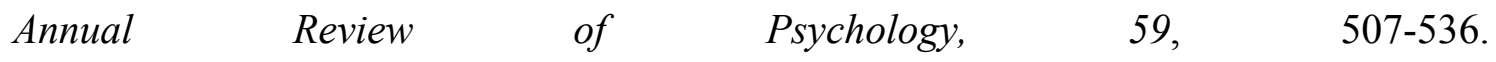
https://doi.org/10.1146/annurev.psych.59.103006.093646

Mayer, J. D., \& Salovey, P. (1997). What is emotional intelligence? In P. Salovey \& D. Sluyter (Eds.), Emotional development and emotional intelligence: Implications for educators (pp. 3-31). New York: Basic Books.

Megías, A., Gómez-Leal, R., Gutiérrez-Cobo, M. J., Cabello, R., \& Fernández-Berrocal, P. (2018a). The relationship between trait psychopathy and emotional intelligence: A metaanalytic review. Neuroscience and Biobehavioral Reviews, 84, 198-203. https://doi.org/10.1016/j.neubiorev.2017.12.003

Megías, A., Gómez-Leal, R., Gutiérrez-Cobo, M. J., Cabello, R., \& Fernández-Berrocal, P. (2018b). The relationship between aggression and ability emotional intelligence: The role of negative affect. Psychiatry Research, 270, 1074-1081. https://doi.org/10.1016/j.psychres.2018.05.027

Navarro-Bravo B, Latorre J. M., Jiménez A, Cabello R, \& Fernández-Berrocal P. (2019). Ability emotional intelligence in young people and older adults with and without depressive symptoms, considering gender and educational level. PeerJ 7:e6595 https://doi.org/10.7717/peerj.6595

O’Boyle, E. H., Humphrey, R. H., Pollack, J. M., Hawver, T. H., \& Story, P. A. (2011). The relation between emotional intelligence and job performance: A meta-analysis. Journal of Organizational Behavior, 32(5), 788-818. https://doi.org/10.1002/job.714

Paton, W. (1993). Man and Mouse: Animals in Medical Research. Oxford: Oxford University Press.

Paul, E. S. (2000). Empathy with animals and with humans: Are they linked? Anthrozoös, 13(4), 194-202. https://doi.org/10.2752/089279300786999699

Paul, E. S. (2005). Love of pets and love of people. In A. L. Podberscek, E. P. Paul, \& J. A. Serpell (Eds.), Companion animals and us. Exploring the relationships between people and pets (pp. 168-186). New York, NY: Cambridge University Press. 
655 Petrides, K. V., Furnham, A., \& Martin, G. N. (2004). Estimates of emotional and psychometric

656

657

658

659

660

661

662

663

664

665

666

667

668

669

670

671

672

673

674

675

676

677

678

679

680

681

682

683

684 intelligence: Evidence for gender-based stereotypes. Journal of Social Psychology, 144, 149-162. https://doi.org/ 10.3200/SOCP.144.2.149-162

Pfattheicher, S., Sassenrath, C., \& Schindler, S. (2015). Feelings for the suffering of others and the environment: Compassion fosters pro-environmental tendencies. Environment and Behavior, 48(7), 929-945. https://doi.org/10.1177/0013916515574549

Preston, S. D., \& de Wall, F. B. (2002). Empathy: Its ultimate and proximate bases. Behavioral and Brain Sciences, 25, 1-72. https://doi.org/10.1017/S0140525X02000018

Ramos, N. S., Fernandez-Berrocal, P., \& Extremera, N. (2007). Perceived emotional intelligence facilitates cognitive-emotional processes of adaptation to an acute stressor. Cognition and Emotion, 21, 758-772. https://doi.org/10.1080/02699930600845846

Ruckert, J. H. (2016). Justice for all? Children's moral reasoning about the welfare and rights of $\begin{array}{llll}\text { endangered } & \text { species. } & \text { Anthrozoos, } & 29,\end{array}$ https://doi.org/10.1080/08927936.2015.1093297

Salovey, P., Bedell, B., Detweiler, J. B., \& Mayer, J. (1999). Coping intelligently: Emotional intelligence and the coping process. In C. R. Snyder (Ed.), Coping: The psychology of what works (pp.141-164). New York: Oxford University Press.

Salovey, P., Mayer, J. D., Goldman, S. L., Turvey, C., \& Palfai, T. F. (1995). Emotional attention, clarity, and repair: Exploring emotional intelligence using the Trait Meta-Mood Scale. In J. W. Pennebaker (Ed.), Emotion, disclosure, and health (pp. 125-154). Washington, DC: American Psychological Association.

Salovey, P., Stroud, L. R., Woolery, A., \& Epel, E. S. (2002). Perceived emotional intelligence, stress reactivity, and symptom reports: Further explorations using the trait meta-mood scale. Psychology and Health, 17, 611-627. https://doi.org/10.1080/08870440290025812

Schieman, S., \& Van Gundy, K. (2000). The personal and social links between age and selfreported empathy. Social Psychology Quarterly, 63, 152-174. https://doi.org/10.2307/2695889

Schutte, N. S., Malouff, J., Bobik, C., Coston, T., Greeson, C., Jedlicka, C., \& Wendorf, G. (2001). Emotional intelligence and interpersonal relations. Journal of Social Psychology, 141, 523-536. https://doi.org/10.1080/00224540109600569 
685 Serpell, J. A. (2004). Factors influencing human attitudes to animals and their welfare. Animal 686 Welfare-potters Bar then Wheathampstead, 13, 145-152.

687 Smith, A. (2006). Cognitive empathy and emotional empathy in human behavior and 688 evolution. The Psychological Record, 56, 3-21. https://doi.org/10.1007/BF03395534

689 Veevers, J. E. (1985). The social meaning of pets: Alternative roles for companion 690 animals. Marriage \& Family Review, 8(3-4), 11-30.

691 World Medical Association (2008). World Medical Association Declaration of Helsinki: Ethical 692 principles for medical research involving human subjects. Retrieved from https://www.wma.net/what-we-do/medical-ethics/declaration-of-helsinki/

694 Young, A., Khalil, K. A., \& Wharton, J. (2018), Empathy for animals: A review of the existing 695 literature. Curator, 61, 327-343. https://doi.org/10.1111/cura.12257

696

697

698

699

700

701

702

703

704

705

706

707

708

709

710 


\section{Table $\mathbf{1}$ (on next page)}

Table 1. Means, standard deviations (SD), and t-test for gender differences. 
1 Table 1. Means, standard deviations (SD), and t-test for gender differences.

\begin{tabular}{|c|c|c|c|c|c|c|c|c|}
\hline & \multicolumn{2}{|c|}{ Total sample } & \multicolumn{2}{|c|}{ Men } & \multicolumn{2}{|c|}{ Women } & \multirow[b]{2}{*}{ t-test } & \multirow[b]{2}{*}{ Cohen's d } \\
\hline & Mean & $\mathrm{SD}$ & Mean & SD & Mean & SD & & \\
\hline $\begin{array}{l}\text { Attention } \\
\text { (TMMS) }\end{array}$ & 3.35 & .88 & 3.15 & .89 & 3.45 & .86 & $-3.49 * *$ & 0.34 \\
\hline Clarity (TMMS) & 3.16 & .83 & 3.24 & .83 & 3.12 & .84 & 1.59 & 0.14 \\
\hline Repair (TMMS) & 3.17 & .76 & 3.23 & .74 & 3.15 & .77 & 1.11 & 0.11 \\
\hline $\begin{array}{l}\text { Perspective- } \\
\text { taking (IRI) }\end{array}$ & 3.57 & .67 & 3.46 & .68 & 3.63 & .66 & $-1.21 * *$ & 0.25 \\
\hline Fantasy (IRI) & 3.23 & .70 & 3.06 & .66 & 3.32 & .70 & $-4.01 * *$ & 0.40 \\
\hline $\begin{array}{l}\text { Empathic concern } \\
\text { (IRI) }\end{array}$ & 4.00 & .61 & 3.66 & .67 & 4.16 & .50 & $-9.19^{* *}$ & 0.85 \\
\hline $\begin{array}{l}\text { Personal distress } \\
\text { (IRI) }\end{array}$ & 2.40 & .77 & 2.25 & .75 & 2.49 & .77 & $-3.19 * *$ & 0.32 \\
\hline $\begin{array}{c}\text { Animal empathy } \\
\text { (AES) }\end{array}$ & 148.39 & 28.28 & 139.84 & 27.03 & 152.85 & 27.97 & $-4.85^{* *}$ & 0.47 \\
\hline
\end{tabular}

$* p<.05, * * p<.01$

2 


\section{Table 2 (on next page)}

Table 2. Pearson's correlations between El and empathy for humans in the total sample. 
1 Table 2. Pearson's correlations between EI and empathy for humans in the total sample.

\begin{tabular}{|c|c|c|c|c|c|c|c|}
\hline $\begin{array}{l}2 \\
3\end{array}$ & 2 & 3 & 4 & 5 & 6 & 7 & 8 \\
\hline $\begin{array}{l}\text { 1.Attention } \\
\text { (TMMS) }\end{array}$ & $.27 * *$ & .06 & $.32 * *$ & $.25^{* *}$ & $.35^{* *}$ & $.20^{* *}$ & $.13^{* *}$ \\
\hline $\begin{array}{l}\text { 2.Clarity } \\
\text { (TMMS) }\end{array}$ & - & $.35^{* *}$ & $.12 *$ & $.10^{*}$ & -.02 & $-.26 * *$ & -.04 \\
\hline $\begin{array}{l}\text { 3.Repair } \\
\text { (TMMS) }\end{array}$ & & - & $.13^{* *}$ & $.24 * *$ & .08 & $-.24 * *$ & .07 \\
\hline $\begin{array}{l}\text { 4.Perspective- } \\
\text { taking (IRI) }\end{array}$ & & & - & $.25^{* *}$ & $.33^{* *}$ & $-.11 *$ & $.13 * *$ \\
\hline 5.Fantasy (IRI) & & & & - & $.35^{* *}$ & $.22 * *$ & $.20 * *$ \\
\hline $\begin{array}{l}\text { 6.Empathic } \\
\text { concern (IRI) }\end{array}$ & & & & & - & $.16^{* *}$ & $.29 * *$ \\
\hline $\begin{array}{c}\text { 7.Personal } \\
\text { distress (IRI) }\end{array}$ & & & & & & - & .03 \\
\hline $\begin{array}{l}\text { 8. Animal } \\
\text { empathy (AES) }\end{array}$ & & & & & & & - \\
\hline
\end{tabular}

$* p<.05, * * p<.01$ 


\section{Table 3(on next page)}

Table 3

Table 3. Pearson's correlations between El and empathy for humans and animals according to pet ownership. 
1 Table 3. Pearson's correlations between EI and empathy for humans and animals according to 2 pet ownership.

\begin{tabular}{lccccccc}
\hline 3 & $\begin{array}{c}\text { Attention } \\
\text { (TMMS) }\end{array}$ & $\begin{array}{c}\text { Clarity } \\
\text { (TMMS) }\end{array}$ & $\begin{array}{c}\text { Repair } \\
\text { (TMMS) }\end{array}$ & $\begin{array}{c}\text { Perspective- } \\
\text { taking (IRI) }\end{array}$ & $\begin{array}{c}\text { Fantasy } \\
\text { (IRI) }\end{array}$ & $\begin{array}{c}\text { Empathic } \\
\text { concern } \\
\text { (IRI) }\end{array}$ & $\begin{array}{c}\text { Personal } \\
\text { distress } \\
\text { (IRI) }\end{array}$ \\
\hline $\begin{array}{c}\text { Animal empathy } \\
\text { (AES) } \\
\text { (Pet owners) }\end{array}$ & $.18^{* *}$ & -.02 & $.14^{*}$ & $.13^{*}$ & $.27^{* *}$ & $.40^{* *}$ & .05 \\
\hline $\begin{array}{c}\text { Animal empathy } \\
\text { (AES) } \\
\text { (Non-pet owners) }\end{array}$ & .11 & -.04 & .02 & $.14^{*}$ & .12 & $.15^{*}$ & .04 \\
\hline
\end{tabular}

$* p<.05,{ }^{* *} p<.01$ 


\section{Table 4 (on next page)}

Table 4. Summary of the hierarchical multiple regression analysis. 
1 Table 4. Summary of the hierarchical multiple regression analysis.

2

\begin{tabular}{|c|c|c|c|c|c|c|c|c|}
\hline Step & Sample & Criterion & Predictors & B & SE & Beta & $\mathbf{t}$ & $p$ \\
\hline \multirow[t]{3}{*}{1} & \multirow[t]{3}{*}{471} & \multirow[t]{3}{*}{$\begin{array}{l}\text { Empathy } \\
\text { for animals }\end{array}$} & Pet owner & -.10 & 2.51 & -.18 & -4.13 & $<.001$ \\
\hline & & & Gender & .12 & 2.61 & .19 & 4.43 & $<.001$ \\
\hline & & & Age & -.31 & .04 & -.11 & -2.50 & $<.05$ \\
\hline \multirow[t]{6}{*}{2} & \multirow[t]{6}{*}{471} & \multirow[t]{6}{*}{$\begin{array}{l}\text { Empathy } \\
\text { for animals }\end{array}$} & Pet owner & -10.95 & 2.50 & -.19 & -4.38 & $<.001$ \\
\hline & & & Gender & 10.65 & 2.64 & .18 & 4.03 & $<.001$ \\
\hline & & & Age & -.24 & .13 & -.08 & -1.85 & .66 \\
\hline & & & $\begin{array}{l}\text { Attention } \\
\text { (TMMS) }\end{array}$ & 3.60 & 1.53 & .11 & 2.33 & $<.05$ \\
\hline & & & Clarity (TMMS) & -2.71 & 1.67 & -.08 & -1.63 & .10 \\
\hline & & & Repair (TMMS) & 4.40 & 1.74 & .12 & 2.52 & $<.05$ \\
\hline \multirow[t]{10}{*}{3} & \multirow[t]{10}{*}{471} & \multirow[t]{10}{*}{$\begin{array}{l}\text { Empathy } \\
\text { for animals }\end{array}$} & Pet owner & -10.96 & 2.46 & -.19 & -4.50 & $<.001$ \\
\hline & & & Gender & 5.92 & 2.78 & .10 & 2.13 & $<.05$ \\
\hline & & & Age & -.26 & .13 & -.09 & -2.00 & $<.05$ \\
\hline & & & $\begin{array}{l}\text { Attention } \\
\text { (TMMS) }\end{array}$ & .95 & 1.70 & .03 & .57 & .57 \\
\hline & & & Clarity (TMMS) & -2.17 & 1.70 & -.06 & -1.30 & .20 \\
\hline & & & Repair (TMMS) & 2.92 & 1.78 & .08 & 1.64 & .10 \\
\hline & & & $\begin{array}{l}\text { Perspective- } \\
\text { taking (IRI) }\end{array}$ & -.31 & 2.04 & -.00 & -.15 & .87 \\
\hline & & & Fantasy (IRI) & 3.13 & 2.01 & .08 & 1.55 & .12 \\
\hline & & & $\begin{array}{l}\text { Empathic concern } \\
\text { (IRI) }\end{array}$ & 9.97 & 2.50 & .22 & 4.07 & $<.001$ \\
\hline & & & $\begin{array}{c}\text { Personal distress } \\
\text { (IRI) }\end{array}$ & -1.52 & 1.80 & -.04 & -.85 & .34 \\
\hline
\end{tabular}

3 
Figure 1

Figure 1. Effect of empathic concern on empathy for animals, moderated by pet ownership.

Values on the $y$-axis represent the levels of empathy for animals. Values on the $x$-axis

represent levels of empathic concern where high and low were specified at - 1 SD (low) and $+1 \mathrm{SD}$ (high) of the centered means. 


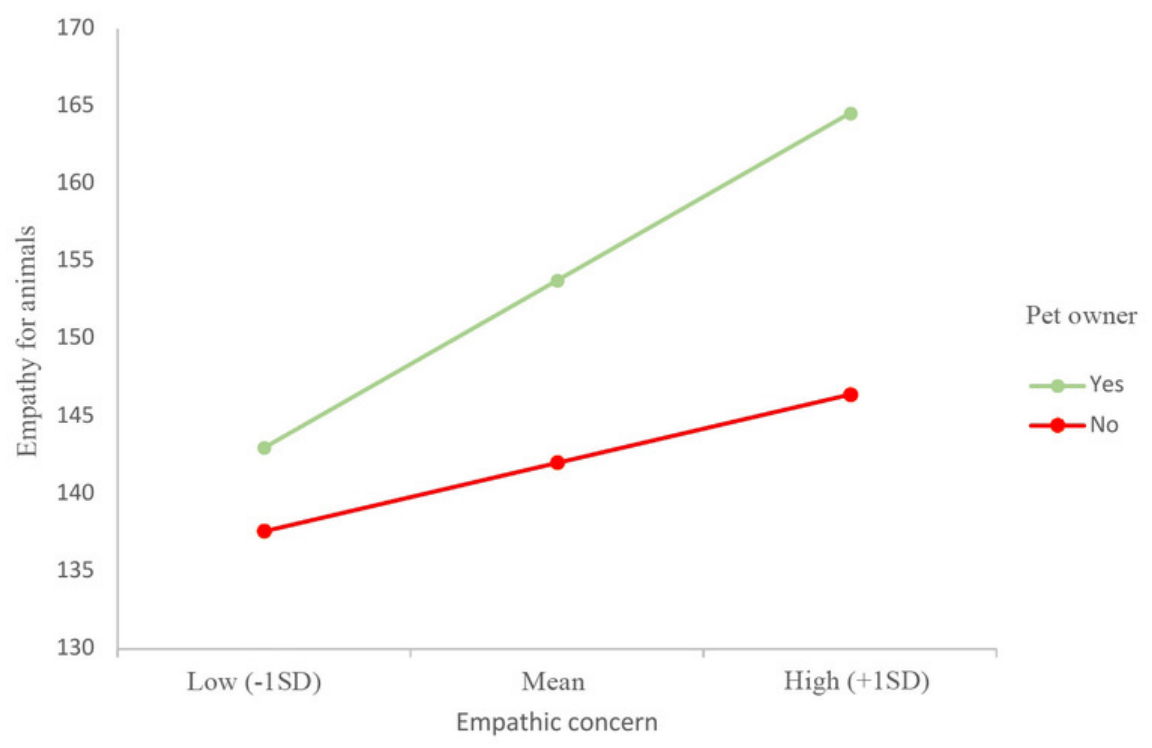

